\title{
CD1A Positive
}

National Cancer Institute

\section{Source}

National Cancer Institute. CD1A Positive. NCI Thesaurus. Code C154049.

An indication that CD1A expression has been detected in a sample. 